\title{
Process Mineralogy as a Basis of Molybdoscheelite Ore Preparation
}

\author{
L. Vaisberg ${ }^{1(\bowtie)}$, O. Kononov ${ }^{2}$, and I. Ustinov ${ }^{1}$ \\ ${ }^{1}$ REC Mekhanobr-Tekhnica, St. Petersburg, Russia \\ gornyi@mtspb.com \\ ${ }^{2}$ Moscow State University, Moscow, Russia
}

\begin{abstract}
The Tyrnyauz ore field (Big Tyrnyauz) is one of the largest and most geologically complex deposits of tungsten and molybdenum. The main valuable mineral of the deposit is molybdoscheelite, a representative of the sheelitepowellite isomorphic series, as well as molybdenite and respective accessory minerals. The main problem in the processing of ores of the Tyrnyauz ore field consists in the high variability of mineral associations of its rocks, including the availability of ores and nonmetallic minerals with similar physical and chemical properties, as well as in the availability of ores of various natural types. Selective mining and processing of various geological and industrial types of ores with a wide use of vibrational technologies for the selective disintegration of raw materials is a promising approach to the development of the Tyrnyauz concentrator.
\end{abstract}

Keywords: Molybdoscheelite - Tungsten $\cdot$ Molybdenum $\cdot$ Disintegration · Separation · Flotation

\section{Introduction}

The Tyrnyauz ore field is located in the North Caucasus and is one of the largest and most geologically complex deposits of tungsten, molybdenum and associated metals. The ore bodies of the Tyrnyauz deposit occur on the platform of Eljurta granites and diabases. In the central part, these have undergone intensive metamorphism and converted into amphibole-biotite hornfelses, overlain by numerous contact-metasomatic and hydrothermal formations. The main valuable minerals of the deposit are molybdoscheelite $\mathrm{Ca}(\mathrm{W}, \mathrm{Mo}) \mathrm{O}_{4}$, a representative of the isomorphous series of scheelite $\mathrm{CaWO}_{4}$ - powellite $\mathrm{CaMoO}_{4}$, and molybdenite.

The deposit had been intensively developed starting from the middle of the XX century. Flotation had always been the main concentration process used at the plant. When the global market for tungsten changed at the end of the XX century, the Tyrnyauz concentrator was shutdown. By that time, the Main Skarn with tungsten and molybdenum mineralization and a significant part of the amphibole-biotite hornfelses with molybdenum mineralization had been mined out. At present, an upgrade of the Tyrnyauz concentrator is required. After the enterprise is repeatedly put into operation, its ore base will be represented by high-calcite skarn ore bodies (up to 10-15\%) and 
skarned marbles with the calcite content of 40-70\%. It is known that calcite and molybdoscheelite have similar flotation properties (Barskyi et al. 1979).

Due to the high calcite to molybdoscheelite ratios, their selective flotation with the use of traditional reagent regimes is impractical. Moreover, at lower mining horizons, scheelite is almost completely replaced by molybdoscheelite, its mineral variety with greater brittleness and lower hardness. These circumstances call for a new mineralogical and technological assessment of the Tyrnyauz deposit. Another independent promising type of ores are talcose hornfelses with high molybdenite contents and associated gold mineralization. However, the availability of a pair of naturally hydrophobic minerals (molybdenite and talc) also hinders their flotation concentration (Tarasevitch et al. 2014).

\section{Methods and Approaches}

Several hundred small and several dozens of large samples of promising ore types were selected and analyzed. Additionally, during the period of active operation of the deposit, the material composition and ore concentration indicators had been continuously analyzed for the respective production processes.

The grain-size distribution of molybdoscheelite (MSh) of different compositions and powellite is due to the regular decrease in hardness and increase in brittleness with the increase in the molybdenum content in the scheelite-powellite series. The higher hydrophobicity of powellite and high-molybdenum MSh (with powellite inclusions), which increases for particles of fine classes due greater specific surface values, predetermines their accumulation in the sulfide-molybdenum concentrate. In contrast, the higher affinity between scheelite and fatty acids, as compared to MSh and powellite, gives certain advantages in the process of rougher scheelite flotation and in respective final treatment.

The dependence of flotation properties of MSh in these operations on the composition, chemical and phase inhomogeneity of the particles enables the use of MSh composition and dispersion values to evaluate the efficiency of flotation processes.

Chemical sampling data on the contents of Mook and WO3, their ratio and related dispersion and the results of MSh local composition analysis serve as the criteria for assessing the chemical inhomogeneity of MSh. The color of luminescence, spectroscopic and kinetic parameters of excitation and radiation represent rapid test indicators for MSh. The color of luminescence is effective when assessing the content of pure scheelite with high hardness and flotability (blue luminescence) and of all varieties of MSh with powellite characterized by low hardness and poor flotability (yellow luminescence). When predicting the processing properties of MSh, dispersion assessment data is of greater significance. Therefore, the criteria used for identifying the processing varieties of ores with account of the composition of MSh should include variations in the composition of pure scheelite, molybdoscheelite and powellite. Similar distribution of molybdenite oxidation values in the ore biotite hornfelses (with almost zero MSh 
content) occurring in parallel to the Slepaya deposit may be used to assess the content and distribution of powellite.

Skarns of the Slepaya deposit do not form independent bodies. These either form part of the metasomatically altered skarned hornfelses, layered and massive marbles, or are represented by relics in the areas of development of later metasomatic mineral associations. In both cases, the skarns are represented by thin lens-shaped and clustered units (with the thickness of several centimeters to several tens of centimeters) having a fine to medium-grained structure with the characteristic light greenish-brown color.

Marbles in the skarn bodies are white, light gray and dark gray massive rocks with a spotted, brecciated or banded texture caused by the alternating interlayers of dark and light marbles of different granularity, alternating interlayers of light marbles and thin banded light green pyroxene-plagioclase hornfelses and new units in the form of wollastonite-fluorite, pyroxene-fluorite and quartz-pyroxene-calcite-garnet veins, veinlets and lenses. The marbles are composed of calcite. The sizes of polysynthetic calcite grains containing fine scattered inclusions of graphite and pyrrhotite range from 0.08 to $1.6 \mathrm{~mm}$.

In the skarned marbles, the distribution of structural, textural and color varieties of marble is non-uniform. Within the contours of the ore body, fine, medium and nonuniformly crystalline and, respectively, dark and light sulfur varieties predominate (in quantitative terms). The lighter and white varieties ("clarified" marbles) form among them a system of veinlets, lens-shaped interlayers, clusters and blocks and are part of the parallel-banded varieties of marbles with calcite bands with a thickness of 1 to $5 \mathrm{~cm}$. Their formation is associated with recrystallization along the fractures and increased permeability zones, as well as in tectonic deformation processes. In addition, lighter zones are always observed at the interfaces between marbles and skarns and around quartz-silicate veins and veinlets.

Luminescent properties of the ore minerals and host rocks of the Tyrnyauz deposit were studied since it is possible to use these luminescent properties as indicators for rapid diagnostics and as separation features in ore separation.

Preliminary concentration of the Tyrnyauz ore, which may be implemented using $\mathrm{X}$-ray luminescent separation (RL), is required due to the processing of comparatively low-grade ores with large amounts of diluting materials and high mineralization contrasts. The contrasts in the luminescent properties of minerals and, therefore, of rocks and ores, may also be used for the rapid diagnostics of various natural and industrial types of ores in the process of their transportation and sorting, for optimizing their grinding conditions, as well as in their subsequent processing. The RL spectra were registered in the continuous and staged scanning modes. In the continuous scanning mode, with the constantly enabled source of excitation, the entire spectrum was recorded. This is the traditional and most informative form of data recording. However, under the influence of X-rays, the luminescence intensity of a substance usually increases. After a certain period of time that is specific for respective centers of luminescence, the saturation level is reached, when the luminescence intensity practically ceases to change or changes so slowly that it produces no effect on the spectrum image at any moment of the scanning time. 
Therefore, reproducible and comparable results in the continuous scanning mode may only be obtained when the samples are irradiated to the saturation state, i.e. for relatively long periods (tens of minutes or more, depending on the mineral). In this connection, a method was developed for expressly obtaining the required information on the spectra by means of high-speed analysis in pulsed mode with staged scanning of the spectrum. Spectral and kinetic RL characteristics were studied for the following minerals: scheelite and molybdenite, calcite, wollastonite, quartz and plagioclase. The resulting RL spectra were interpreted by comparison of the data obtained with the reference data. For all minerals, respective types of luminescence centers were determined and the issues of variability in luminescent properties were considered. For the spectra obtained, the intensities, positions of the maximum and half-widths of the intrinsic luminescence band associated with the [WO4] and [MoO4] groups were established, as well as the wavelength and the intensity of the luminescence lines for impurity ions of rare-earth elements isomorphically replacing calcium ions in the scheelite structure.

\section{Results and Discussion}

Visual observation of the luminescence for the molybdoscheelite samples studied showed that many of them are characterized by a non-uniform color glow (blue and yellow), which indicates joint availability of several varieties of scheelite. In this case, the experimentally studied RL spectrum is composed of individual spectra of these varieties and represents an averaged characteristic for the scheelites of the sample. The scheelite and molybdoscheelite samples studied are characterized by varying degrees of chemical composition inhomogeneity, which is manifested in different colors of their fluorescent luminescence. The half-width of the band of intrinsic luminescence may be used as the inhomogeneity measure.

The observed diversity of the spectra may be explained by the presence of different types of MSh in different sample groups with varying content ratios and by the presence of their spectra. Based on the spectroscopic data obtained, at least four varieties with different luminescent properties may be distinguished for the scheelite samples studied. Signs of vertical zoning are observed in the distribution of MSh with different types of luminescence spectra. At the uppermost horizons, the luminescence intensity is usually higher.

The luminescence and afterglow spectra for all calcite samples studied consist of a single broad band with the luminescence maximum of $630 \mathrm{~nm}$ (orange-red). It was also found that luminescence intensity is variable and depends on a number of parameters, such as the duration of x-ray irradiation, the concentration of manganese, and the color of the samples. An important element of the promising processing technology for the Tyrnyauz ores is the use of selective vibration in disintegration and classification of raw materials. 


\section{Conclusions}

These studies in the field of process mineralogy of molybdoscheelite ores of the Tyrnyauz deposit form the basis for the design of a new combined process flow using various selective vibration methods for disintegration and preliminary lump separation.

Acknowledgements. The study was supported by the grant of the Russian Science Foundation (project No. 17-79-30056).

\section{References}

Barskyi LA, Kononov OV, Ratmirova LI (1979) Selective flotation of calcium minerals. Nedra, Moscow

Tarasevich Y, Aksenenko EV (2014) The hydrophobicity of the basal surface of talc. Colloid J 76(4):526-532

Open Access This chapter is licensed under the terms of the Creative Commons Attribution 4.0 International License (http://creativecommons.org/licenses/by/4.0/), which permits use, sharing, adaptation, distribution and reproduction in any medium or format, as long as you give appropriate credit to the original author(s) and the source, provide a link to the Creative Commons license and indicate if changes were made.

The images or other third party material in this chapter are included in the chapter's Creative Commons license, unless indicated otherwise in a credit line to the material. If material is not included in the chapter's Creative Commons license and your intended use is not permitted by statutory regulation or exceeds the permitted use, you will need to obtain permission directly from the copyright holder.

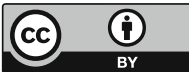

